\title{
Muscle satellite cell proliferation and association: new insights from myofiber time-lapse imaging
}

\author{
Ashley L Siegel ${ }^{1,2}$, Paige K Kuhlmann ${ }^{1,2}$, DDW Cornelison ${ }^{1,2^{*}}$
}

\begin{abstract}
Background: As the resident stem cells of skeletal muscle, satellite cells are activated by extracellular cues associated with local damage. Once activated, satellite cells will re-enter the cell cycle to proliferate and supply a population of myoblasts, which will repair or replace damaged myofibers by differentiating and fusing either with an existing myofiber or with each other. There is also evidence that the orientation of cell division with respect to the myofiber may indicate or convey asymmetry in the two daughter cells. Our recent studies with time-lapse imaging of myofiber-associated satellite cells in vitro have yielded new data on the timing and orientation of satellite cell divisions, and revealed persistent differences in the behavior of daughter cells from planar versus vertical divisions.

Results: We analyzed 244 individual fiber-associated satellite cells in time-lapse video from 24 to 48 hours after myofiber harvest. We found that initial cell division in fiber culture is not synchronous, although presumably all cells were activated by the initial trauma of harvest; that cell cycling time is significantly shorter than previously thought (as short as 4.8 hours, averaging 10 hours between the first and second divisions and eight hours between the second and third); and that timing of subsequent divisions is not strongly correlated with timing of the initial division. Approximately $65 \%$ of first and $80 \%$ of second cell divisions occur parallel to the axis of the myofiber, whereas the remainder occur outside the plane of the fiber surface (vertical division). We previously demonstrated that daughter cells frequently remain associated with each other after division or reassociate after a brief separation, and that unrelated cells may also associate for significant periods of time. We show in this paper that daughter cells resulting from a vertical division remain associated with one another several times longer than do daughters from a horizontal division. However, the total average time of association between sister cells is not significantly different from the total average time of association between unrelated cells.
\end{abstract}

Conclusions: These longitudinal characterizations of satellite cell behavior shortly after activation provide new insights into cell proliferation and association as a function of relatedness, and indicate significant and consistent heterogeneity within the population based on these metrics.

\section{Background}

Satellite cells are the resident stem cells of skeletal muscle; they are considered to be self-renewing, and serve to generate a population of differentiation-competent myoblasts that will participate as needed in muscle growth, repair and regeneration [1,2]. In mature muscle tissue, satellite cells occur as a small, dispersed population of mitotically and physiologically quiescent cells, marked by their expression of the transcription factor Pax7 [3] and

\footnotetext{
* Correspondence: cornelisond@missouri.edu

'Division of Biological Sciences, University of Missouri, Columbia, MO, USA
} Full list of author information is available at the end of the article several cell-surface markers, including CD34 [4], CXCR4 [5], syndecan-4 [6] and $\alpha 7$ integrin [7].

Because of their relative rarity and overall dispersion in the tissue, a useful method of visualizing satellite cells resident on relatively short muscles (either small muscles of larger animals such as rat, or muscles of a small animal such as mouse) is single-fiber isolation and culture [8-10]. Not only are satellite cells (once activated) clearly visible under the light microscope, but they can also be observed over time in relation to their parent myofiber and to other satellite cells resident on the same fiber. When fixed and stained with immune reagents, protein expression and localization can be observed in the
C Biomed Central

(c) 2011 Siegel et al; licensee BioMed Central Ltd. This is an Open Access article distributed under the terms of the Creative Commons Attribution License (http://creativecommons.org/licenses/by/2.0), which permits unrestricted use, distribution, and reproduction in any medium, provided the original work is properly cited. 
context of the host myofiber and other satellite cells associated with the same fiber.

We have recently described a method of following fiber-associated satellite cells longitudinally over extended periods of time in vitro, using time-lapse microscopy [11]. This provides an advantage in characterizing satellite cell activity because we can directly visualize and follow individual satellite cells through multiple phases of activity, including exit from the basal lamina, proliferation, and movement along the myofiber. Although our previous work focused primarily on cell motility and the cellular and environmental factors required for efficient movement on the myofiber, a number of other activities were noted, including a much higher than expected degree of asynchrony in the timing of satellite cell divisions, and a surprising tendency for cells to both remain as cell doublets for extended periods of time after cell division and to associate as apparent doublets with unrelated cells. These behaviors would have a significant effect on interpretation and analysis of fixed and stained cell preparations, so we set out to tabulate and quantify these aspects of satellite cell activity after activation.

\section{Results}

We analyzed 244 individual fiber-associated satellite cells over a 24-hour period, beginning at 24 hours after fiber harvest. All cells were considered 'activated' based on their rounded morphology, position outside the external lamina, and motility. For each cell, the time and axis of each cell division, the length of time the daughter cells remained associated, and any subsequent divisions or cell-cell associations (either with related or unrelated cells) were noted. All cultures contained fibroblast growth factor FGF2, a potent survival factor, but no other exogenous cytokines except those present in 15\% horse serum. Cell by cell division data can be found in Table S1; Additional File 1. The data was extracted from movies available in Additional files 2, 3, 4, 5, 6, 7, 8 and 9.

\section{Timing of initial and subsequent proliferation}

We found that, unlike results reported previously that were based on autoradiographic [8] or immunohistochemical [12] studies of cell cycle markers, neither the first division of satellite cells after harvest nor the subsequent divisions are synchronous when they are observed directly by time-lapse video. In our study, $16 \%$ of cells were never seen to divide; the remainder could undergo the first observed cell division at any time from 24 to 48 hours (Figure 1a). Subsequent divisions occurred in $65 \%$ of daughters anywhere from 5.1 to 17.8 hours after the first detected division (with an average cycling time of 10.0 hours), and $20 \%$ of cells divided a third time within the 24 hour observation period, 4.8 to 13.3 hours after the second division (with an average cycling time of 7.9 hours) (Figure 1b). These observed times are significantly shorter than the 16 to 18 hour cell cycle generally assumed for recently activated satellite cells [12].

\section{Orientation of division (horizontal versus vertical) with respect to the host myofiber}

Among the $84 \%$ of cells that divided at least once during the 24 hours, $65 \%$ appeared to have an axis of division parallel to the myofiber axis (horizontal division) at the first division, whereas the other $35 \%$ had an axis of division perpendicular to the myofiber axis (vertical division) (Figure 1c, with representative cell divisions shown in Figure 1d). A small number of divisions were of indeterminate orientation and were not counted. Vertical divisions are therefore somewhat more prevalent in our dataset than observed in previous studies of planar versus apical division that used genetically marked satellite cells [13]. However, that study required a pair of fixed cells to be oriented vertically with respect to the fiber at the time of fixation, whereas in our time-lapse observations, we noted that frequently after a vertical division the cell doublet rapidly 'tipped' to leave both cells in contact with the myofiber (as would be observed in a horizontal division). The previous study was also only conducted at one timepoint ( 42 hours after harvest) and included determination of both symmetric and asymmetric marker gene expression. There may therefore have been some undersampling in that study, to the extent that similar cell activities were being measured. Interestingly, we found that vertical division with respect to the myofiber was not restricted to the first cell division, but also occurred in subsequent divisions: $20 \%$ of second divisions and $6 \%$ of third divisions observed in the 24 to 48 hour timeframe were also scored as occurring vertically (Figure 1a, b). To test whether the probability of dividing either vertically or horizontally was influenced by the orientation of the previous division, we performed a Pearson $\chi^{2}$ test; the calculated $\chi^{2}$ was 0.62 , indicating that the null hypothesis is true and they are independent events. There also appeared to be no specific time period in which vertical divisions were more prevalent (Figure 1a).

\section{Association between related and non-related cells}

A significant result of our previous time-lapse studies is that satellite cells occurring in closely associated doublets are not necessarily the product of a recent cell division: sister cells may remain associated for many hours after cell division, and motile satellite cells may encounter unrelated cells and appear as doublets in still images [11]. This complicates the analysis of proliferation and lineage history when evaluating fixed, stained populations of fiber-associated satellite cells, particularly with regard to establishing the relatedness 


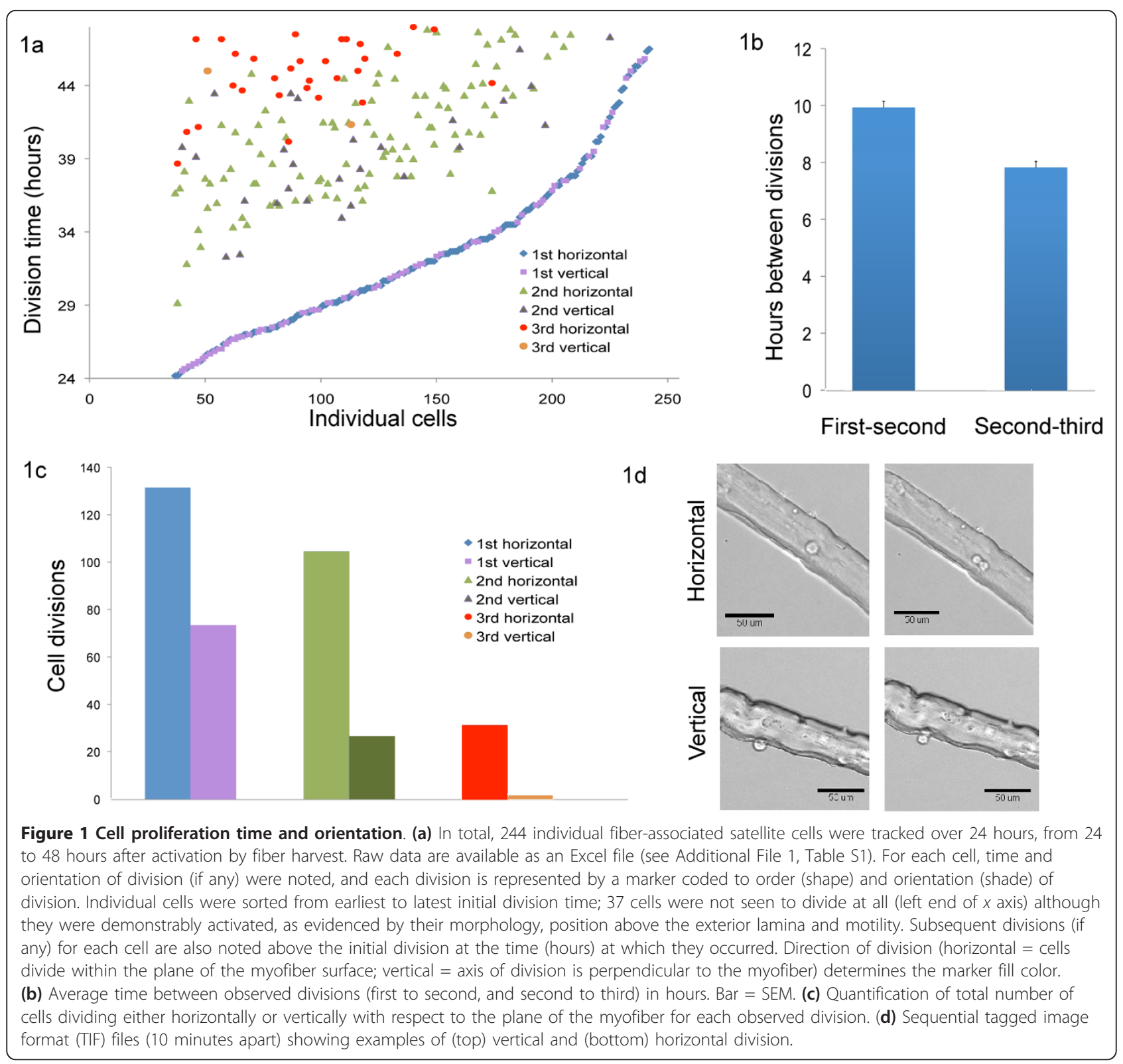

of two heterogeneously staining cells. We found that there was only a slight preference for association with 'sister' rather than 'stranger' cells (Figure 2a), even though sister cells are in contact immediately after cell division and therefore would seem more likely to associate. Interestingly, those cells participating in non-sister cell associations could interact with up to four other non-sister cells in the 24 hour timeframe we examined (Figure 2b).

\section{Association between daughters of horizontal versus vertical divisions}

Overall, the slight tendency to prefer 'sister' cells over 'stranger' cells in the population as a whole is due almost entirely to the significantly extended association times noted for daughters of vertical rather than horizontal divisions: the average association time between daughter cells from an initial vertical division was 8.4 hours, versus 2.3 hours for daughters from an initial horizontal division (Figure 2c). Sister cells that separated also occasionally reassociated and extended their total association time (Figure 2c). While both time of association for daughters of a vertical division and the fraction of cells dividing vertically decreased for second and third cell divisions, both of these phenomena were still prevalent. Averaged across all cells for the entire time period, cells with a history of vertical division were 


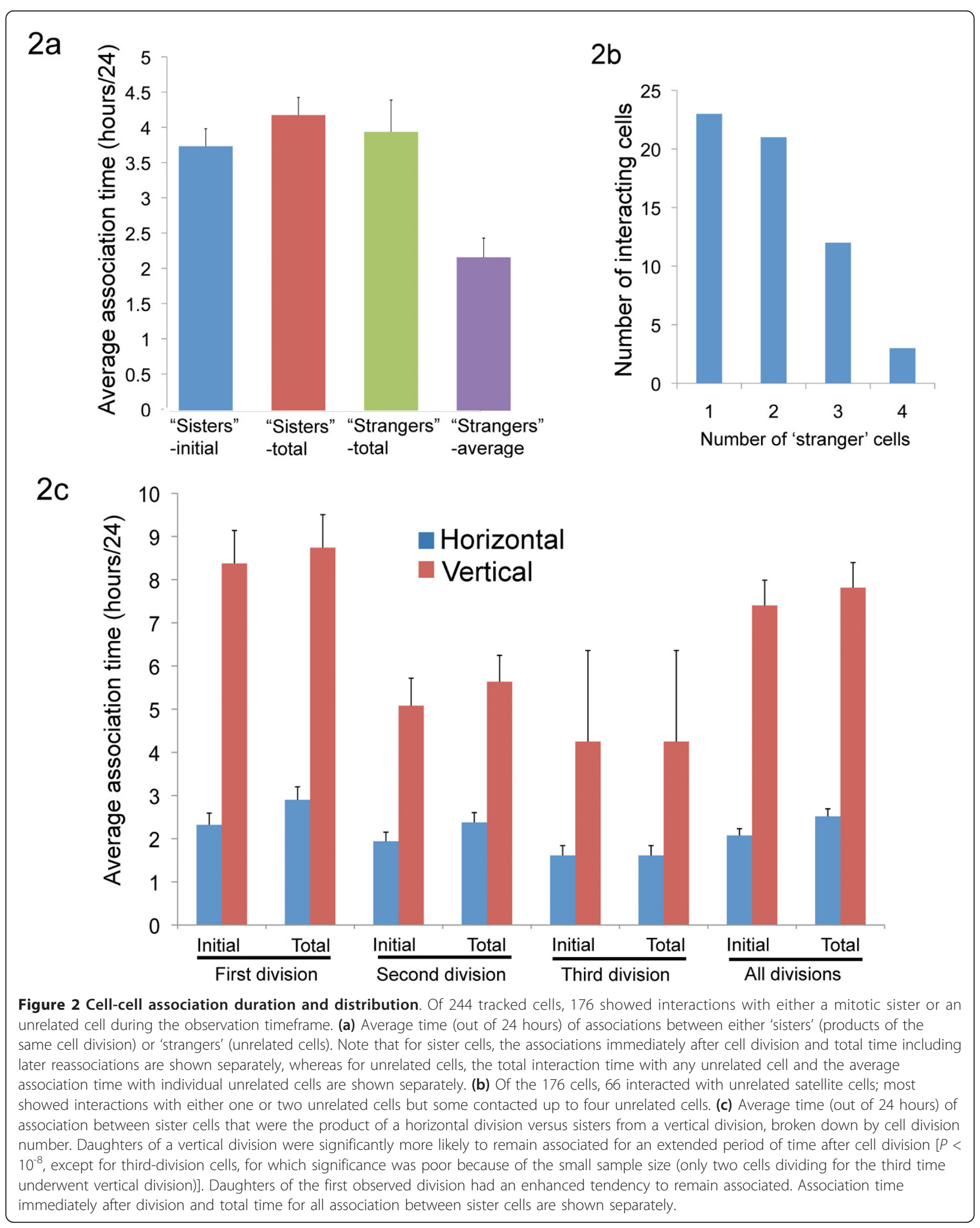


associated with sister cells for 7.8 hours, compared with 2.5 hours for the majority of cells resulting from exclusively horizontal divisions (Figure 2c).

\section{Discussion}

We recently published a method by which single living myofiber explants together with their associated satellite cells are embedded in a collagen I gel, and the activity and motility of the satellite cells is captured by timelapse video. It is important to emphasize that this system preserves some aspects of the in vivo influences available to the satellite cells but explicitly lacks others (including all secreted factors that would be produced by non-muscle cell types in vivo). The extracellular matrix (ECM), in particular, provides structural, adhesive and signaling cues to adherent cells, and probably influences multiple cellular activities.

The exterior lamina of the myofiber is composed primarily of collagen IV and laminin-2 (merosin) linked by entactin/nidogen [14]; the collagen forms the layer closest to the myofiber, whereas the laminin is more superficial. Therefore, when satellite cells reside beneath the basement membrane, they can encounter both collagen IV and laminin-2, whereas after they emerge from the sarcolemmal space, they encounter primarily laminin. When we stained for collagen IV and laminin after enzymatic myofiber harvest, both remained intact compared with non-enzymatically separated myofibers, except for localized areas of laminin depletion at sites of satellite cell exit (Siegel et al., manuscript in preparation). However, other ECM components that are not specifically associated with the myofiber lamina, including factors that have been shown to affect skeletal muscle regeneration, such as perlecan [15], would not be maintained in this system. Particularly in the context of vertical division, in which the 'top' cell in our culture would not be in contact with any physiological substrate besides its 'bottom' sister, this is a caveat to bear in mind.

Biophysical substrate properties have also been shown to affect cell activity: recent work from the Blau laboratory [16] has shown that satellite cell lineage choice and division behavior is regulated by substrate stiffness, with exposure to physical environments that are more similar to the elasticity of muscle tissue promoting enhanced stem-cell character and myogenic activity. The stiffness of the collagen I gel used in these experiments is calculated to be $\sim 16 \mathrm{kPa}$ [17], which is similar to the physiological stiffness of muscle in vivo (12 kPa) [16], thus the total surface of the satellite cells (on the myofiber and at the gel interface) is exposed to physiologically appropriate substrate pressure. Therefore, although the mechanical and structural components of this ex vivo system are more similar than other culture methods to a true in vivo environment, because it consists of only a single fiber embedded in a low-complexity matrix there are undoubtedly significant differences as well (including ones we are not yet aware of.)

We have previously derived quantitative data regarding cell velocity and directionality from sets of fiber-associated satellite cells viewed with time-lapse microscopy [11], but a significant amount of qualitative data remains to be extracted even from movies of experimentally untreated cells. The most surprising result from these analyses is that, contrary to most current thought in the field, initial cell division after myofiber harvest is quite asynchronous. We noted cell divisions occurring at all time points within the window we analyzed ( 24 to 48 hours after myofiber harvest). This could imply asynchrony in activation of individual satellite cells, followed by a consistent lag until initial division, or even asynchronous activation followed by a variable interval until the first division. However, this seems unlikely based on existing data regarding geneexpression changes associated with activation, and on our own observations of initiation of motility and subsequent exit from the sublaminar niche. In addition, whereas previous reports suggested a consistent cell-cycling time of about 17 to 18 hours [12] for satellite cells in fiber culture, we observed not only a much shorter average proliferation time (9.6 hours) but also a highly variable proliferation interval between the first, second and third divisions. It seems more likely that both the timing and length of the cell cycle are evidence of heterogeneity within the population for which we have not yet identified key mediators. Ideally, future experiments correlating expression of labeled candidate proteins with time-lapse analysis will provide insight into the molecular basis for this variation.

Such heterogeneity in individual satellite cell activity also appears to be supported by analysis of sister cell associations after either a vertical or horizontal division. Recently, compelling evidence has emerged that orientation of cell division with respect to the myofiber is predictive of both gene expression and stem-cell status $[13,18]$. We show here that orientation of division also correlates with subsequent cell behavior. Daughter cells resulting from cell divisions occurring in a vertical or planar division (which has been previously been associated with asymmetric stem-cell divisions, at a rate of $\sim 10 \%$ of all divisions [13]) remained physically associated for several times longer (in some cases, for the remainder of the filming period after division, 23+ hours) than did daughters of a horizontal division. Although the reason for such prolonged contact is not yet clear, it is intriguing to speculate that extended contact-mediated signaling between a daughter cell that retains stem-cell characteristics and one that has committed to eventual myogenic differentiation (which would be expected based on genetic labeling studies 
$[13,19])$ may contribute to maintenance of the asymmetric fates. Contact-mediated reciprocal signaling, particularly through the Notch-Delta pathway, has been shown in other systems to reinforce asymmetric fates; further studies into paired-cell signaling may therefore be instructive.

\section{Conclusions}

Time-lapse imaging is unlikely to replace analysis of fixed cell populations for many practical reasons. These include the time- and labor-intensive nature of the imaging and analysis, plus the difficulty of simultaneous visualization of molecular markers. The current study provides an analysis of general satellite cell morphometrics over a time period that is pertinent to the interpretation of fixed cell data. We reached four major conclusions: 1) Initial cell divisions following the activation of satellite cells by trauma signals produced during the myofiber harvest process are highly asynchronous, and the timing between subsequent cell divisions indicates a highly variable cell cycling time that is significantly shorter than previously reported. 2) Approximately $25 \%$ of all cell divisions occurring within the 24 to 48 hour time period are planar, with the axis of division perpendicular to the axis of the host myofiber. 3) When two cells are in close contact with one another, they are almost equally likely to be unrelated to each other as they are to be daughters of a single cell division. 4) Daughter cells resulting from a vertical division are 2 to 3 times more likely to be found associating with each other at any given point in time than are daughter cells of a horizontal division.

\section{Methods}

\section{Myofiber harvest and culture}

Viable myofiber explants from 80 to 130-day-old B6D2F1 female mice (Jackson) were prepared according to our published techniques $[6,10,20]$. Briefly, muscle was dissected from the hind limbs, carefully separated from associated tissues and digested in $400 \mathrm{U} / \mathrm{ml} \mathrm{col-}$ lagenase type I (Worthington Biochemical, Lakewood NJ) diluted in Ham's F-12 medium (Invitrogen, Carlsbad $\mathrm{CA})$. When single fibers are liberated, they are manually picked with a pipette and cultured at $37^{\circ}$ and $5 \% \mathrm{CO}_{2}$ in growth medium (Ham's F-12 (Invitrogen), 15\% horse serum (Equitech Bio, Kerrville TX) and penicillin/streptomycin (Invitrogen, Carlsbad CA) supplemented with $0.5 \mathrm{nmol} / \mathrm{L}$ recombinant human FGF-2] for 24 hours before being transferred into 48-well plates for timelapse analysis.

\section{Time-lapse capture}

Myofibers were embedded in $200 \mu \mathrm{l}$ per well of $2 \mathrm{mg} / \mathrm{ml}$ acid-extracted rat tail type I collagen [21] in growth medium in 48-well plates (Corning Costar). After polymerization, the wells were overlaid with growth medium containing $0.5 \mathrm{nmol} / \mathrm{L}$ FGF-2. Multiple fields under $\times 10$ magnification were identified per well and marked for return. Images were collected automatically from each field every 10 minutes using IPLab (Scanalytics, Rockville MD) or MetaMorph (Molecular Devices, Sunnyvale CA).

\section{Post-imaging analysis}

Stacked tagged image format (TIF) files generated by IPLab were imported into MetaMorph and arranged in sequential order. Cells were selected for analysis if they were 1 ) visible during the entire 24 hour imaging period, 2) distinguishable from other cells for the duration of the movie, and 3) associated with a viable myofiber for the duration of the movie. If a cell selected for tracking divided during the 24-hour collection period, one daughter cell was selected at random to continue the trace. For each cell, we noted the frame number(s) showing cell division, if any, the frame numbers during which the cell was in physical contact with another satellite cell, and the relationship between the two cells, if any. Frame numbers were converted to time after myofiber harvest for analysis.

\section{Additional material}

Additional file 1: Table S1: Division timing and orientation data for all cells. All 244 cells analyzed are listed by movie number (available as additional files 2, 3, 4, 5, 6, 7, 8, 9) and cell number. For each cell, time (in hours after myofiber harvest) and orientation of each division ( $\mathrm{H}=$ horizontal; $\mathrm{N}=$ no division; $\mathrm{V}=$ Vertical) is noted.

Additional file 2: contains movies 1-15.

Additional file 3 : contains movies $16-30$

Additional file 4: contains movies 31-45

Additional file 5: contains movies 46-60.

Additional file 6: contains movies 61-75.

Additional file 7: contains movies 76-90

Additional file 8: contains movies 91-105

Additional file 9: contains movies 106-121

\section{Acknowledgements}

This work was supported by NIH R21 AR056814-01 to DDWC. PKK is supported by the University of Missouri Mathematics in Life Sciences Program and NSF PRISM grant DMS-0928053 (Dix Pettey, Director and P.I).

\section{Author details}

'Division of Biological Sciences, University of Missouri, Columbia, MO, USA. ${ }^{2}$ Christopher S. Bond Life Sciences Center, University of Missouri, Columbia, MO, USA.

Authors' contributions

ALS and DDWC were responsible for myofiber harvest and culture. ALS performed the time-lapse imaging. PKK tabulated cell divisions and associations. DDWC conceived of the study, participated in its design and coordination, and wrote the manuscript. All authors read and approved the final manuscript. 


\section{Competing interests}

The authors declare that they have no competing interests.

Received: 6 October 2010 Accepted: 2 February 2011

Published: 2 February 2011

\section{References}

1. Hawke TJ, Garry DJ: Myogenic satellite cells: physiology to molecular biology. J Appl Physiol 2001, 91:534-551.

2. Shi X, Garry DJ: Muscle stem cells in development, regeneration, and disease. Genes Dev 2006, 20:1692-1708.

3. Seale P, Sabourin LA, Girgis-Gabardo A, Mansouri A, Gruss P, Rudnicki MA Pax7 is required for the specification of myogenic satellite cells. Cell 2000, 102:777-786.

4. Beauchamp JR, Heslop L, Yu DS, Tajbakhsh S, Kelly RG, Wernig A, Buckingham ME, Partridge TA, Zammit PS: Expression of CD34 and Myf5 defines the majority of quiescent adult skeletal muscle satellite cells. J Cell Biol 2000, 151:1221-1234.

5. Ratajczak MZ, Majka M, Kucia M, Drukala J, Pietrzkowski Z, Peiper S, Janowska-Wieczorek A: Expression of functional CXCR4 by muscle satellite cells and secretion of SDF-1 by muscle-derived fibroblasts is associated with the presence of both muscle progenitors in bone marrow and hematopoietic stem/progenitor cells in muscles. Stem Cells 2003, 21:363-371.

6. Cornelison DDW, Filla MS, Stanley HM, Rapraeger AC, Olwin BB: Syndecan-3 and syndecan-4 specifically mark skeletal muscle satellite cells and are implicated in satellite cell maintenance and muscle regeneration. Dev Biol 2001, 239:79-94.

7. Blanco-Bose WE, Yao CC, Kramer RH, Blau HM: Purification of mouse primary myoblasts based on alpha 7 integrin expression. Exp Cell Res 2001, 265:212-220.

8. Bischoff R: Regeneration of single skeletal muscle fibers. Anat Rec 1975, 182:215-235.

9. Rosenblatt JD, Lunt Al, Parry DJ, Partridge TA: Culturing satellite cells from living single muscle fiber explants. In Vitro Cell Dev Biol Anim 1995, 31:773-779.

10. Cornelison DDW, Wold BJ: Single-cell analysis of regulatory gene expression in quiescent and activated mouse skeletal muscle satellite cells. Dev Biol 1997, 191:270-283.

11. Siegel AL, Atchison K, Fisher KE, Davis GE, Cornelison DDW: 3D time-lapse analysis of muscle satellite cell motility. Stem Cells 2009, 27:2527-2538.

12. Zammit PS, Heslop L, Hudon V, Rosenblatt JD, Tajbakhsh S, Buckingham ME, Beauchamp JR, Partridge TA: Kinetics of myoblast proliferation show that resident satellite cells are competent to fully regenerate skeletal muscle fibers. Exp Cell Res 2002, 281:39-49.

13. Kuang S, Kuroda K, Le Grand F, Rudnicki MA: Asymmetric self-renewal and commitment of satellite stem cells in muscle. Cell 2007, 129:999-1010.

14. Sanes JR: The basement membrane/basal lamina of skeletal muscle. J Biol Chem 2003, 278:12601-12604.

15. Henriquez JP, Casar JC, Fuentealba L, Carey DJ, Brandan E: Extracellular matrix histone $\mathrm{H} 1$ binds to perlecan, is present in regenerating skeletal muscle and stimulates myoblast proliferation. I Cell Sci 2002, 115:2041-2051.

16. Gilbert PM, Havenstrite KL, Magnusson KE, Sacco A, Leonardi NA, Kraft P, Nguyen NK, Thrun S, Lutolf MP, Blau HM: Substrate elasticity regulates skeletal muscle stem cell self-renewal in culture. Science 2010, 329:1078-1081.

17. Roeder BA, Kokini K, Sturgis JE, Robinson JP, Voytik-Harbin SL: Tensile mechanical properties of three-dimensional type I collagen extracellular matrices with varied microstructure. J Biomech Eng 2002, 124:214-222.

18. Le Grand F, Jones AE, Seale V, Scime A, Rudnicki MA: Wnt7a activates the planar cell polarity pathway to drive the symmetric expansion of satellite stem cells. Cell Stem Cell 2009, 4:535-547.

19. Kuang $S$, Gillespie MA, Rudnicki MA: Niche regulation of muscle satellite cell self-renewal and differentiation. Cell Stem Cell 2008, 2:22-31.

20. Capkovic KL, Stevenson S, Johnson MC, Thelen JJ, Cornelison DDW: Neural cell adhesion molecule (NCAM) marks adult myogenic cells committed to differentiation. Exp Cell Res 2008, 314:1553-1565.

21. Davis GE, Camarillo CW: Regulation of endothelial cell morphogenesis by integrins, mechanical forces, and matrix guidance pathways. Exp Cell Res 1995, 216:113-123. doi:10.1186/2044-5040-1-7

Cite this article as: Siegel et al: Muscle satellite cell proliferation and association: new insights from myofiber time-lapse imaging. Skeletal Muscle 2011 1:7.

\section{Submit your next manuscript to BioMed Central and take full advantage of:}

- Convenient online submission

- Thorough peer review

- No space constraints or color figure charges

- Immediate publication on acceptance

- Inclusion in PubMed, CAS, Scopus and Google Scholar

- Research which is freely available for redistribution 